\title{
Evaluation of hippuric acid content in goat milk as a marker of feeding regimen
}

\author{
A. Carpio, ${ }^{*}$ D. Bonilla-Valverde, † C. Arce, $¥$ V. Rodríguez-Estévez, ${ }^{1}$ M. Sánchez-Rodríguez, $\ddagger$ L. Arce, ${ }^{*}$ \\ and M. Valcárcel* \\ *Department of Analytical Chemistry, Institute of Fine Chemistry and Nanochemistry, University of Córdoba, Annex C3 Building, \\ Campus of Rabanales, E-14071 Córdoba, Spain \\ †Centro de Investigación y Calidad Agroalimentaria de Los Pedroches (CICAP) Research, Apdo. Correos 105, Ctra. de la Canaleja s/n, \\ 14400 Pozoblanco, Córdoba, Spain \\ ‡Department of Animal Production, University of Córdoba, Campus of Rabanales, E-14071 Córdoba, Spain
}

\begin{abstract}
Organic producers, traders, and consumers must address 2 issues related to milk: authentication of the production system and nutritional differentiation. The presence of hippuric acid (HA) in goat milk samples has been proposed as a possible marker to differentiate the feeding regimen of goats. The objective of this work is to check the hypothesis that HA could be a marker for the type of feeding regimen of goats by studying the influence of production system (conventional or organic) and feeding regimen (with or without grazing fodder). With this purpose, commercial cow and goat milk samples $(\mathrm{n}=27)$ and raw goat milk samples $(\mathrm{n}=$ 185; collected from different breeds, localizations, and dates) were analyzed. Samples were grouped according to breed, feeding regimen, production system, and origin to compare HA content by ANOVA and honestly significant difference Tukey test at a confidence level of $\geq 95 \%$. Hippuric acid content was obtained by analyzing milk samples with capillary electrophoresis. This method was validated by analyzing part of the samples with HPLC as a reference technique. Sixty-nine raw goat milk samples (of the total 158 samples analyzed in this work) were quantified by capillary electrophoresis. In these samples, the lowest average content for HA was $7 \pm 3 \mathrm{mg} / \mathrm{L}$. This value corresponds to a group of conventional raw milk samples from goats fed with compound feed. The highest value of this group was $28 \pm 10 \mathrm{mg} / \mathrm{L}$, corresponding to goats fed compound feed plus grass. Conversely, for organic raw goat milk samples, the highest concentration was $67 \pm 14 \mathrm{mg} / \mathrm{L}$, which corresponds to goats fed grass. By contrast, the lowest value of this organic group was $26 \pm 10 \mathrm{mg} / \mathrm{L}$,
\end{abstract}

Received November 20, 2012

Accepted May 27, 2013.

${ }^{1}$ Corresponding author: pa2roesv@uco.es which belongs to goats fed organic compounds. Notice that the highest HA average content was found in samples from grazing animals corresponding to the organic group. This result suggests that HA is a good marker to determine the type of goats feeding regimen; a high content of HA represents a diet based mainly or exclusively on eating green grass (grazing), independently of the production system. Hence, this marker would not be useful for the actual organic policies to distinguish organic milk under the current regulations, because organic dairy ruminants can be fed organic compound feed and conserved fodder without grazing at all.

Key words: authentication, organic farming, capillary electrophoresis, high performance liquid chromatography

\section{INTRODUCTION}

In recent decades, debate has been growing about the ethical aspects of production and trade. The International Federation of Organic Agriculture Movements defines organic livestock production as a system based on the harmonious relationship between land, plants and livestock, respect to the physiological and behavioral needs of livestock, and using organically grown foodstuffs or natural resources as fodders (IFOAM, 2002). Consumers associate organic farming with grazing animals (fodder diet, freedom, and welfare); however, the standards for organic livestock farming detailed by the organic farming regulations of the European Community (Council of the European Union, 2007) allow an intensive open air production, without grazing and feeding animals with organic compound feeds adding green or conserved fodder (e.g., silage, hay, straw, and so on). Producers, traders, and consumers of organic food regularly use the concept of the natural (naturalness) to characterize organic farming and organic food, in contrast to the unnaturalness of conventional farming. Critics sometimes argue that such use lacks any 
rational (scientific) basis and only refers to sentiment (Verhoog et al., 2003).

On the basis of a systematic review from a total of 52,471 articles about nutritional quality of foods, Dangour et al. (2009) identified 162 studies (137 crop and 25 livestock products) dealing with organic food; only 55 were of satisfactory or higher quality. Those authors established that the analysis of the very limited database on livestock products found no evidence of a difference in nutrient content between organically and conventionally produced livestock products. Hence, organic producers, retailers, and consumers must address 2 issues related to food: authentication of the production methods and nutritional differentiation.

In the case of organic milk, different techniques have been used for nutritional differentiation. Many authors have compared the composition and content of FA between organic and conventional milk (Ellis et al., 2006; Collomb et al., 2008; Molkentin, 2009, Molkentin and Giesemann, 2010). Ellis et al. (2006) found that organic milk had a higher proportion of PUFA and n-3 FA, and this effect of production system remained significant even after accounting for some potentially confounding management and nutritional factors in the analyses. Collomb et al. (2008) also found a higher content in PUFA, conjugated linoleic acids, and branched FA in organic milk with significantly higher levels of grasses and lower levels of concentrates in the fodder of organic farming.

Other authors have also carried out different comparisons in the composition and content of different analytes between organic and conventional milk samples to find suitable markers to certify the milk production system and avoid fraud. Molkentin (2009) studied the influence of the production system (organic or conventional) and the season by measuring the carbon-stable isotope ratio $\left(\delta^{13} \mathrm{C}\right)$ using isotope-ratio mass spectrometry, and the content of $\alpha$-linoleic acid in milk using gas chromatography. These parameters were selected because both of them are measured in the easily accessible milk fat. Molkentin (2009) concluded that $\delta^{13} \mathrm{C}$ and $\alpha$-linoleic acid are not good markers to discriminate between organic and conventional milk; one of the main reasons being the seasonal variation showed by both components. They also investigated their applicability as markers for authentication of organic milk in Germany, due to its higher content in organic milk. However, they did not consider the feeding regimen of animals (only the production system).

Furthermore, Molkentin and Giesemann (2010) concluded that analyses involving the combination of threshold values for $\delta^{13} \mathrm{C}, \delta^{15} \mathrm{~N}$, or $\mathrm{C} 18: 3 \mathrm{n}-3$ content in milk components can improve the authentication of organic milk. Thus, multivariable analyses can increase robustness and reduce the number of exceptions in organic milk authentication.

After the determination of a mixture of organic acids (oxalic, citric, orotic, benzoic, uric, and hippuric acids) in milk samples, Carpio et al. (2010) found that only hippuric acid (HA) could be a marker to distinguish milk from goats fed on different production system. However, these authors concluded that it is necessary to check if the HA content comes from grazing fodder or from organic handling.

This initial hypothesis, highlighted by Carpio et al. (2010), is supported by the conclusions summarized by other authors. Some of the first articles that mentioned the natural presence of HA in cow milk were those presented by Karabinos and Dittiner (1943), Patton (1953), and Svensen (1974). According to Sieber et al. (1995), HA concentration of cow milk may be up to $50 \mathrm{mg} / \mathrm{kg}$, although Patton (1953) found that HA concentration ranged from 31 to $64 \mathrm{mg} / \mathrm{L}$ in skim milk. Svensen (1974) observed a higher amount of HA in milk from grazing than from indoor forage feeding. Also, Besle et al. (2010) found a higher content of HA in milk from cows with a diet based on grazing grassland pasture in comparison to those with a diet based on different diets of concentrate and silage or hay forages. Besle et al. (2010) related milk HA to the presence of chlorogenic acid, neochlorogenic acid, or caffeoyl compounds in the diets based on grassland pasture (per Gonthier et al., 2003). Forages contain large amounts of aromatic compounds both in the insoluble cell wall and in the cellular content in the form of water and ethanol-soluble polyphenols specific to each plant taxon. These aromatic compounds, including HA, are partially degraded in the rumen and partly absorbed in the rumen and intestinal mucosa, following an immediate conjugation before they are transformed in the liver and excreted in urine or milk (Gatley and Sherratt, 1977; Scheline, 1991). Hence, an important factor in the variation of content of aromatic compounds in milk samples could be the feeding regimen and the fodder quality that goats have consumed, which are seasonally influenced by climatic conditions of the area and the month of sample collection (Peinado-Lucena et al., 1992).

The aim of the present work was, first, to check the hypothesis proposed by Carpio et al. (2010), that the evaluation of HA in goat milk samples is a possible marker to differentiate the type of feeding regimen supplied to goats; second, to validate capillary electrophoresis $(\mathbf{C E})$ to determine HA content by a reference technique, such as HPLC; and third, elucidate if the differences in HA content between organic and conventional milk are due to feeding regimen more than production system (organic or conventional). 
Table 1. Total commercial milk samples analyzed

\begin{tabular}{llllc}
\hline $\begin{array}{l}\text { Production } \\
\text { system }\end{array}$ & Animal & Breed & Origin & $\begin{array}{c}\text { Number } \\
\text { of samples }\end{array}$ \\
\hline Conventional & Cow & Holstein-Friesian & Spain & 11 \\
& Cow & British Friesian & United Kingdom & 3 \\
& Goat & Murciano-Granadina & Spain & 1 \\
Organic & Goat & Saanen and Alpine & United Kingdom & 2 \\
& Cow & Holstein-Friesian & Spain & 4 \\
& Cow & British Friesian & United Kingdom & 5 \\
& Goat & Murciano-Granadina & Spain & 1 \\
\hline
\end{tabular}

\section{MATERIALS AND METHODS}

\section{Samples, Chemicals, and Standards}

Goat milk samples analyzed in this work are individual raw milk from farms and commercial milk from markets, with a total of 162 organic and conventional goat milk samples. Most of these were raw goat milk samples $(\mathrm{n}=158)$. As only 4 different commercial goat milk brands were found in the Spanish and English markets (only 1 of them being organic), it was decided to include commercial cow milk samples to increase the size of this group. For this reason, 23 samples of commercial cow milk (organic and conventional) were also analyzed (see Table 1). All commercial conventional cow milk samples were whole and UHT, and all commercial conventional goat milk samples were semiskimmed by UHT or pasteurization processes. To obtain the highest number of commercial organic milk samples, all the samples found in the market were included in this study. Raw goat milk samples were grouped into 9 groups according to breed, feeding regimen, production system, and origin (zone); each group corresponds to a different farm (see Table 2).

Raw milk samples were collected in situ into sterile $30-\mathrm{mL}$ plastic screw-top containers and farm production information (production system, feeding regimen, and diet) was obtained by an interview with the farmer. Note that each sample was from 1 individual goat, not from a tank. Samples were transported cold to the lab- oratory, where all samples were frozen at $-80^{\circ} \mathrm{C}$ until their analysis. Commercial milk samples were analyzed immediately after opening.

Hippuric acid (CAS Number 495-69-2) with a purity of $98 \%$ was supplied by Sigma (St. Louis, MO). A stock standard solution containing a $1,000 \mathrm{mg} / \mathrm{L}$ of HA was prepared in purified water. Working standard solutions were prepared by diluting the stock standard solution with purified water. Sodium tetraborate decahydrate was obtained from Sigma and cetyl trimethyl ammonium bromide from Fluka (Buchs, Switzerland). All water used was purified by passing through a Milli-Q apparatus from Millipore (Bedford, MA).

\section{Sample Preparation}

Commercial milk samples were bought pasteurized. This treatment may produce losses of compounds that form part of the milk (including HA). To study the stability of HA in the pasteurization process, a cow raw milk sample and another from goat were taken from milk companies tanks. These milk samples came from different animals fed in conventional farms. The study was carried out analyzing 2 aliquots of each cow and goat milk samples before pasteurizing it, and 2 aliquots after the pasteurization process (3 replicates from each aliquot were analyzed).

The steps followed to extract a mixture of organic acids present in milk samples were a reoptimization

Table 2. Total raw milk samples analyzed

\begin{tabular}{|c|c|c|c|c|c|c|c|}
\hline $\begin{array}{l}\text { Production } \\
\text { system }\end{array}$ & $\begin{array}{l}\text { Feeding } \\
\text { regimen }\end{array}$ & Animal & Breed & Origin & $\begin{array}{l}\text { Sampling } \\
\text { month }\end{array}$ & $\begin{array}{l}\text { Number } \\
\text { of samples }\end{array}$ & Group \\
\hline \multirow[t]{4}{*}{ Conventional } & Feed & Goat & Florida & Córdoba (Spain) & December 2010 & 11 & 1 \\
\hline & Feed & Goat & Murciano-Granadina & Sevilla (Spain) & December 2010 & 11 & 2 \\
\hline & Feed + grazing & Goat & Serrana & Badajoz (Spaín) & December 2010 & 11 & 3 \\
\hline & Feed & Goat & Florida & Badajoz (Spain) & February 2011 & 10 & 4 \\
\hline \multirow[t]{5}{*}{ Organic } & Grazing & Goat & Payoya & Cádiz (Spain) & Multiple $^{1}$ & 61 & 5 \\
\hline & Feed & Goat & Murciano-Granadina & Murcia (Spain) & January 2011 & 14 & 6 \\
\hline & Grazing & Goat & Serrana & Huelva (Spain) & June-July 2011 & 20 & 7 \\
\hline & Feed & Goat & Serrana & Córdoba (Spain) & April 2012 & 10 & 8 \\
\hline & Grazing & Goat & Serrana & Badajoz (Spain) & April 2012 & 10 & 9 \\
\hline
\end{tabular}

\footnotetext{
${ }^{1}$ Samples were collected in May, June, and July 2010; January 2011; and April 2012.
} 
of the process proposed by Buiarelli et al. (2003); these are shown in detail in a previous work (Carpio et al., 2010). In summary, a volume of $9 \mathrm{~mL}$ of milk was deproteinated by a simple addition of $2 \mathrm{M} \mathrm{HCl}$ to lower the $\mathrm{pH}$ to 3.4 to 3.6 . Then, the extract was defatted and the residual proteins were eliminated by centrifugation. Finally, the separated whey was filtered through $0.45-\mu \mathrm{m}$ filters (Terumo, Leuven, Belgium) to remove any particle that might block the capillary or the column, and the sample was ready for injection. All the samples were analyzed 3 times to obtain an average value of each sample.

\section{Apparatus and Operating Conditions}

The $\mathrm{pH}$ of the samples was adjusted with a MicropH 2000 from Crison (Barcelona, Spain). Samples were centrifuged with a high-speed centrifuge with microprocessor control from J.P.Selecta S.A. (Abrera, Barcelona, Spain). Analytes were separated and quantified on a P/ ACE MDQ capillary electrophoresis system instrument from Beckman (Palo Alto, CA) equipped with a diode array detector and using a fused-silica capillary (Beckman Coulter) of $75 \mu \mathrm{m}$ i.d., a total length of $60.2 \mathrm{~cm}$, and an effective separation length of $50 \mathrm{~cm}$.

Capillary electrophoresis operating conditions were similar to those previously used by Buiarelli et al. (2003), but reoptimized for this particular purpose (Carpio et al., 2010). The running buffer consisted of $120 \mathrm{~m} M$ sodium tetraborate decahydrate and $0.5 \mathrm{mM}$ cetyl trimethyl ammonium bromide adjusted to $\mathrm{pH}$ 8 with hydrochloric acid. The applied voltage was 10 $\mathrm{kV}$, the average current was $150 \mu \mathrm{A}$, and the working temperature was $25^{\circ} \mathrm{C}$. Samples were injected in the hydrodynamic mode at 0.5 psi for $5 \mathrm{~s}$. Electropherograms were recorded at $200 \mathrm{~nm}$ using reversed polarity. All buffer solutions and milk whey samples were filtered through a nylon membrane with a $0.45-\mu \mathrm{m}$ pore size (Terumo) before analysis.

Prior to first use, the capillary was conditioned by rinsing with $1 \mathrm{M} \mathrm{HCl}$ for $5 \min , 0.1 \mathrm{M} \mathrm{NaOH}$ for 10 min, and water for 5 min, using a pressure of 20 psi in all cases. The capillary was prepared for daily use by rinsing with $0.1 \mathrm{M} \mathrm{NaOH}$ for $5 \mathrm{~min}$, water for $5 \mathrm{~min}$, and separation buffer for $15 \mathrm{~min}$, with a pressure of 20 psi. Between individual analyses, the capillary was conditioned with water for 5 min and separation buffer for 5 min before injection. After 6 injections, an extra rinse cycle was included as a blank analysis.

The HPLC analyses were carried out using a Varian 920-LC analytical chromatograph equipped with a photodiode array detector (Varian Inc., Mulgrave, Australia). A C18 reversed-phase column (5 $\mu \mathrm{m} ; 250$ $\times 4.6 \mathrm{~mm}$; Phenomenex, Torrance, CA) was used. Hip- puric acid was eluted at isocratic flow rate of $1 \mathrm{~mL} /$ min, with a mobile phase of acetonitrile-water-acetic acid (12.5:86.5:1). The UV detection wavelength was set at $229 \mathrm{~nm}$. All analyses were performed at room temperature and the volume of solution injected into the column was $20 \mu \mathrm{L}$ for each run.

\section{Comparison Between Data Obtained with CE and with HPLC}

Results obtained for the milk samples analyzed by $\mathrm{CE}$ were validated using a separation technique widely employed in routine laboratories, such as HPLC. For this comparison study, 33 raw conventional goat milk samples, 36 raw organic goat milk samples, and 9 commercial milk samples (organic and conventional milk) were analyzed simultaneously by CE and HPLC.

Before analyzing the milk samples by HPLC, a calibration curve was calculated showing a linear response between 1 and $100 \mathrm{mg} / \mathrm{L}$ and a correlation coefficient of 0.9981. A study of precision was also carried out with standard solutions of HA at 2 levels of concentration, 10 and $100 \mathrm{mg} / \mathrm{L}$. Precision was assessed in terms of repeatability and reproducibility (as \% relative standard deviation, RSD). Repeatability in the peak area was calculated by injecting HA $(\mathrm{n}=9)$. Reproducibility in the peak area was calculated by injecting HA during 3 consecutive days, preparing a different solution for each day.

\section{Analytical Strategies Followed to Compare the Results from Analyzed Milk Samples}

Different strategies were followed to compare data (peak area or concentration of HA) obtained from 2 different equipment (CE and HPLC).

Strategy 1. A standard addition method was used to determine the exact concentration of HA present in commercial milk samples. The standard addition method is a useful, but time-consuming tool to quantify compounds in complex samples (such as milk); with this methodology the matrix effect is avoided. In this work, the same set of commercial samples was analyzed with 2 different techniques (HPLC and CE).

Strategy 2. The area value of the HA peak was used to compare the content of HA from the different samples analyzed (raw milk samples) using the same equipment. This strategy was the simplest one used in this work, as the data from the electropherogram or chromatogram can be directly used to determine the related content of HA from a big set of samples avoiding the quantification step, which is time consuming.

Strategy 3. Finally, a direct quantification of the HA present in raw milk samples by using calibration 
Table 3. Content of hippuric acid in commercial milk samples analyzed by capillary electrophoresis using the standard addition method

\begin{tabular}{llcc}
\hline Type of milk & Animal & $\begin{array}{c}\text { Total number } \\
\text { of brands }\end{array}$ & $\begin{array}{c}\text { Concentration } \\
(\mathrm{mg} / \mathrm{L})\end{array}$ \\
\hline Conventional & Cow & 14 & $14 \pm 8^{\mathrm{a}}$ \\
\multirow{2}{*}{ Organic } & Goat & 3 & $12 \pm 3^{\mathrm{a}}$ \\
& Cow & 9 & $15 \pm 8^{\mathrm{a}}$ \\
& Goat & 1 & $35 \pm 9^{\mathrm{b}}$ \\
\hline
\end{tabular}

${ }_{\mathrm{a}, \mathrm{b}}$ Mean values with the same letters indicate homogeneous subsets for $P=0.01$ according to Tukey's honestly significant difference test.

${ }^{1}$ Average $\pm \mathrm{SD}$.

curves was used to compare the results obtained for CE and HPLC. This strategy was used only when the number of samples analyzed was high and we could not afford to run the standard addition method to calculate the exact concentration of each sample. In this case, the strategy 2 (peak area values) could not be used to compare results, as they were obtained with 2 different techniques (HPLC and CE). For this reason, calibration curves were used to obtain an approximated concentration value (as matrix effects were not considered).

\section{Statistical Analysis}

The statistics software package SPSS 14.0 (SPSS, Chicago, IL) was used for statistical analysis. The values obtained for samples (conventional or organic and with or without grazing) were compared statistically by ANOVA and Tukey honestly significant difference (HSD) test at 3 confidence levels (95, 99, and 99.9\%). In addition, the statistical significance test of Student's $t$-test was applied to data of milk samples analyzed using both techniques (CE and HPLC) to confirm if the results were comparable at a confidence level of 95\%. The calibration curves for CE and HPLC method were obtained using Excel software (Microsoft Corp., Redmond, WA).

\section{RESULTS AND DISCUSSION}

\section{Determination of HA in 2 types of Commercial Milk Samples (Organic and Conventional)}

Values of peak areas for HA in the electropherograms remained practically constant before and after the pasteurization process of raw milk. Therefore, HA concentration is not affected by the pasteurization treatment; consequently, it could be used as a potential marker for differentiating the feeding regimen of the animals analyzing any type of milk (raw and pasteurized).

Once the study of HA stability in the pasteurization process was carried out, the content of HA in commercial milk samples (conventional and organic) was calculated using the standard addition method (strategy 1). The average and standard deviation values are similar for conventional cow and goat milk samples $(P=0.01)$, as well as between these and organic cow milk samples (Table 3; note that all samples in this table were found in different supermarkets from Spain and United Kingdom). Unfortunately, only 1 brand of organic commercial goat milk was found in the market. However, all its samples resulted in the highest HA content (with a mean value of $35 \mathrm{mg} / \mathrm{L}$ ), significantly different from the other milk brands analyzed $(P=$ 0.01 ). The last data confirm the initial hypothesis, that organic goat milk samples have higher values of HA than conventional goat milk samples (Carpio et al., 2010); but the same conclusion cannot be extrapolated to the organic cow samples.

Because the standards for organic livestock farming (Council of the European Union, 2007) allow an intensive production (without grazing) of animals fed organic compound feeds with added green or conserved fodder, we developed a second hypothesis: Could HA be a marker to distinguish the feeding regimen of goats, but not the production system (organic or conventional)?

\section{Determination of HA in 2 Types of Raw Goat Milk Samples (Organic and Conventional)}

Table 4 shows the average and standard deviation of the peak area values of HA for each group of samples corresponding to the same goat breed and localization. As the number of samples analyzed was large, area peak values (strategy 2 ) obtained by $\mathrm{CE}$, and not concentration, were used in this study. Data shown in Table 4 are represented in Figure 1. As can be seen in Figure 1 , the highest values of HA $(398,925$ and 363,886$)$ correspond, respectively, to organic raw milk samples of Payoya breed goats (group 5) and Serrana breed goats from Badajoz (group 9), both of which graze. Conversely, the lowest and most homogeneous values $(31,968)$ correspond to conventional raw milk samples of Murciano-Granadina breed goats (group 2), followed 


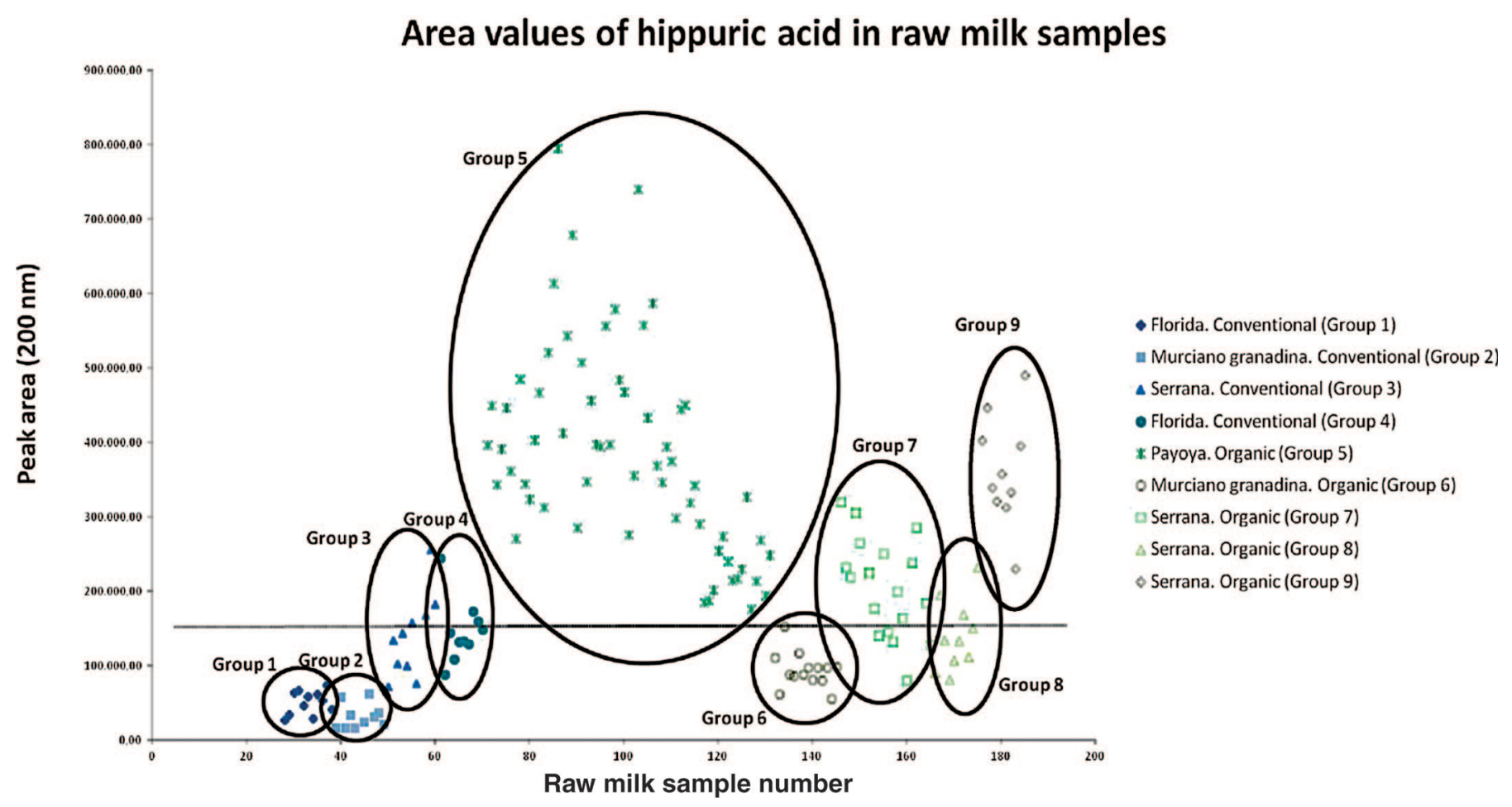

Figure 1. Peak area values of hippuric acid corresponding to the electropherograms at $200 \mathrm{~nm}$ of raw milk samples analyzed. Color version available in the online PDF.

by Florida breed goats (group 1) values $(51,317)$, which did not graze.

Figure 1 attempts to establish a peak area value to be used as the cut-off level between organic and conventional raw milk samples. Two groups of organic milk (groups 6 and 8) might be easily misclassified as conventional (see Figure 1), as they have a low-to-medium value of HA (94,547 and 141,148, respectively). Table 5 shows the peak area values of HA for different dates corresponding to a same organic flock with a diet based on grazing (group 5). Statistically significant differences exist between different months $(P=0.05)$, the summer months being those with the highest values. This fact can be explained taking into account that the feeding regimen and the fodder quality the goats have consumed are seasonally influenced by climatic conditions of the area and the month of sample collection (Peinado-Lucena et al., 1992).According to PeinadoLucena et al. (1992), during summer, the grazing goat diet is more dependent of shrub and tree fodder; hence,

Table 4. Average and standard deviation of peak area values of hippuric acid in each group of raw goat milk samples

\begin{tabular}{lcllcr}
\hline Type of milk & Group & $\begin{array}{l}\text { Feeding } \\
\text { regimen }\end{array}$ & $\begin{array}{l}\text { Goat } \\
\text { breed }^{1}\end{array}$ & $\begin{array}{c}\text { Total number } \\
\text { of samples }\end{array}$ & $\begin{array}{c}\text { Peak area } \\
\text { value }\end{array}$ \\
\hline Conventional & 1 & Feed & F & 11 & $51,317 \pm 16,001^{\text {ab }}$ \\
& 2 & Feed & MG & 11 & $31,968 \pm 16,738^{\mathrm{a}}$ \\
& 3 & Feed + grazing & S & 11 & $139,714 \pm 55,799^{\text {ab }}$ \\
Organic & 4 & Feed & F & 10 & $146,866 \pm 42,253^{\text {bc }}$ \\
& 5 & Grazing & P & 61 & $398,925 \pm 143,737^{\mathrm{d}}$ \\
& 6 & Organic feed & MG & 14 & $94,547 \pm 23,617^{\text {ab }}$ \\
& 7 & Grazing & S & 20 & $237,698 \pm 53,014^{\mathrm{c}}$ \\
& 8 & Organic feed & S & 10 & $141,148 \pm 47,816^{\mathrm{b}}$ \\
& 9 & Grazing & $\mathrm{S}$ & 10 & $363,886 \pm 73,958^{\mathrm{d}}$ \\
\hline
\end{tabular}

${ }^{\mathrm{a}-\mathrm{d}}$ Mean values with the same letters indicate homogeneous subsets for $P=0.05$ according to Tukey's honestly significant difference test.

${ }^{1} \mathrm{~F}=$ Florida; $\mathrm{MG}=$ Murciano-Granadina; $\mathrm{S}=$ Serrana; $\mathrm{P}=$ Payoya. 
Table 5. Average and SD of peak area values of hippuric acid in raw organic Payoya goat milk samples (group 5) from different dates

\begin{tabular}{lcc}
$\begin{array}{l}\text { Sampling } \\
\text { month }\end{array}$ & $\begin{array}{c}\text { Total number } \\
\text { of samples }\end{array}$ & $\begin{array}{c}\text { Peak area } \\
\text { value }\end{array}$ \\
\hline May 2010 & 12 & $391,152 \pm 64,258^{\mathrm{a}}$ \\
June 2010 & 12 & $490,296 \pm 153,144^{\mathrm{b}}$ \\
July 2010 & 12 & $486,689 \pm 125,940^{\mathrm{b}}$ \\
January 2011 & 9 & $377,295 \pm 52,030^{\mathrm{a}}$ \\
April 2012 & 16 & $248,286 \pm 42,326^{\mathrm{c}}$ \\
Total samples & 61 & $398,925 \pm 143,737$
\end{tabular}

${ }^{\mathrm{a}-\mathrm{c}}$ Mean values with the same letters indicate homogeneous subsets for $P=0.05$ according to Tukey's honestly significant difference test.

this change of the grazing date could explain the HA differences.

Conversely, milk samples of group 6 (see Table 2) and a subgroup of group 5 (see Table 5) were collected in the same month (January). However, the HA content is almost 4 times higher in raw milk from group 5 than in group 6 (398,925 vs. 94,547; $P=0.001$; see Table 4). Both groups are organic, but the group 6 diet is based on organic compound feed, whereas group 5 is completely grazing dependent.

Finally, we can conclude that, in group 5 (Payoya breed goats), a high content of HA exists because its diet is based on grazing fodder. These data confirm the experimental values of a previous work (Carpio et al., 2010) where the average and standard deviation of the peak areas of raw organic milk samples from Payoya breed goats collected in February and April 2009 were 430,293 $\pm 100,283$, similar to the high values obtained from samples analyzed in this study $(398,925$ $\pm 143,737)$.

Carrying on with this hypothesis, when comparing feeding regimen instead of production system (Table 6 ), the highest HA peak area values correspond to the grazing samples (all of them organic; 362,445 \pm $178,620$ vs. $94,025 \pm 53,040 ; P=0.001)$. Similarly, the difference between diets (grazing or feed) is higher than the one between the production regimens (organic or conventional; 312,053 vs. 86,$458 ; P=0.001$ ) because the values of the samples from animals fed organic com- pound feed (with an average of 108,774 ) reduce the HA average of organic milk samples.

According to these data, HA could be a good marker of the type of feeding regimen of goats. A high content of HA would represent a diet based mainly or exclusively on eating green grass or fresh fodder (grazing). However, this would not represent organic farming because the organic rules do not imply grazing. Hence, this marker would not be useful for the actual organic policies under the current regulations, because organic dairy ruminants can be fed with organic compound feed and conserved fodder without grazing at all.

Differences between raw conventional goat milk could be explained by variations in the commercial feed composition, considering that this is usually formulated for the lowest cost. Furthermore, the high standard deviations of Payoya goat samples (in group 5 and previous studies) could be explained by individual variations of diet, which are proper for foraging animals (PeinadoLucena et al., 1992; Rodríguez-Estévez et al., 2009). In this sense, Collomb et al. (2008) take into account the fodder composition to compare organic and conventional milk, and Besle et al. (2010) find differences in milk HA content related to the presence of caffeoylquinic compounds in forages. Hence, the high difference in HA content found in the samples analyzed could be due to climatic and soil factors affecting growth and botanical composition of fodder in each geographical zone.

\section{Comparison Between the Data Obtained with CE and with HPLC}

The analytical methodology proposed by Carpio et al. (2010) was validated with a classical analytical technique found in agrifood laboratories such as HPLC. In both cases, the same samples were analyzed. Commercial milk samples were quantified using the standard addition method (strategy 1 ) by $\mathrm{CE}$ and its values were compared with the results obtained by HPLC. The results of both techniques (CE and HPLC) are $15 \pm 3$ and $13 \pm 3 \mathrm{mg} / \mathrm{L}$ for conventional milk, respectively, and

Table 6. Average and SD of peak area values of hippuric acid in raw goat milk samples according to feeding and production regimen

\begin{tabular}{lcc}
\hline & $\begin{array}{c}\text { Total } \\
\text { number } \\
\text { of samples }\end{array}$ & $\begin{array}{c}\text { Peak area } \\
\text { value }\end{array}$ \\
Group & 115 & $312,053 \pm 190,101^{\mathrm{a}}$ \\
Total organic samples & 43 & $86,458 \pm 57,295^{\mathrm{b}}$ \\
Total conventional samples (all feed samples) & 91 & $362,445 \pm 178,620^{\mathrm{a}}$ \\
Total grazing samples & 67 & $94,025 \pm 53,040^{\mathrm{b}}$ \\
Total compound feed samples & 24 & $108,774 \pm 40,055^{\mathrm{b}}$ \\
Total organic and feed samples & \multicolumn{1}{c}{${ }^{\mathrm{b}}$} & \\
a,b Mean values with the same letters indicate homogeneous subsets for $P=0.0001$ according to Tukey's hon- \\
estly significant difference test.
\end{tabular}


$12 \pm 4$ and $16 \pm 8 \mathrm{mg} / \mathrm{L}$ for organic milk, respectively. The Student's test of the total average values obtained for conventional milk analyzed with both techniques does not show significant differences at a confidence level of $95 \%$. Hence, the results obtained by HPLC and $\mathrm{CE}$ are comparable. Besides, the Student's test carried out to compare the total average values in organic milk leads to the same conclusion.

From these data, it can also be concluded that HA is not a good marker to distinguish if pasteurized milk is organic or not; probably because organic milk can be obtained by feeding goats or cows organic compound feed. These organic compounds are produced by companies, and can be bought and supplied to the animals.

Raw conventional and organic goat milk samples were also analyzed by HPLC and CE methods. The average concentration values and standard deviation obtained (see strategy 3) from raw milk samples by HPLC and $\mathrm{CE}$ are shown in Table 7 . It can be seen that similar results were obtained using both techniques, the total average in conventional and organic milk, respectively, are statistically comparable using the Student's test at a level of confidence of $95 \%$.

As mentioned before, the Murciano-Granadina breed of goats (group 2) is the group with lowest content of HA. This low value could be explained by the fact that the food provided to these goats was based on conventional compound feed. The low standard deviation also obtained confirms that all the goats had the same diet (compound feed). Hence, the individual variation proper of foraging animals was not expected. The complete opposite was found in the Serrana breed of goats (group 3). For those goats, the highest content of HA was found among the conventional milk group, as they had grazed despite their conventional farming system. However, this was an extensive regimen with foraging and individual variations of grazing diet, highlighting the high standard deviation $( \pm 10)$ found in the samples analyzed by HPLC and CE, respectively.

Conversely, the results of analyzing raw organic milk using both techniques also show values statically comparable according to the Student's test $(P=0.05)$. For these results, the deviation values are higher than for conventional milk samples, which indicate the variability of the grazing fodder ingested by the goats.

Finally, the average values of $\mathrm{HA}$ obtained by $\mathrm{CE}$ after analyzing conventional and organic raw goat milk are $14 \pm 10$ and $45 \pm 19 \mathrm{mg} / \mathrm{L}$, respectively. Hence, it can be concluded that the HA content in the organic raw milk analyzed is higher than in conventional milk, and it can be due to a higher ingestion of green or conserved fodder following the organic regulations (Council of the European Union, 2007).

\section{CONCLUSIONS}

Hippuric acid content depends on the feeding regimen (with or without grazing) more than on the production system (organic or conventional). We confirmed that HA is not a suitable marker to certify and label goat milk as organic, as organic milk production has to only pass the minimum standard of feeding organic feed and fodder (green or conserved), but it does not imply grazing. The double analysis carried out with $\mathrm{CE}$ and HPLC served to validate the electrophoresis methodology to measure HA and reinforces the experimental data obtained. Finally, for a successful valuation program of dairy ruminant organic farming and the milk produced, it would be necessary to promote not only the general principles of the International Federation of Organic Agriculture Movements, but also specific feeding rules requiring grazing, which is closer to consumer perception of organic milk than the current minimum standards. Then, it would be necessary and useful to

Table 7. Average values of hippuric acid concentration obtained by HLPC and capillary electrophoresis (CE) in conventional and organic raw goat milk samples (mean $\pm \mathrm{SD}$ )

\begin{tabular}{llccc}
\hline $\begin{array}{l}\text { Type } \\
\text { of milk }\end{array}$ & Goat breed & $\begin{array}{c}\text { Total number } \\
\text { of samples }\end{array}$ & $\begin{array}{c}\text { HPLC } \\
(\mathrm{mg} / \mathrm{L})\end{array}$ & $\begin{array}{c}\text { CE } \\
(\mathrm{mg} / \mathrm{L})\end{array}$ \\
\hline Conventional & Florida (group 1) & 11 & $12 \pm 3^{\mathrm{a}}$ & $11 \pm 3^{\mathrm{a}}$ \\
& Murciano-Granadina (group 2) & 11 & $5 \pm 2^{\mathrm{a}}$ & $7 \pm 3^{\mathrm{a}}$ \\
& Serrana (group 3) & 11 & $26 \pm 10^{\mathrm{b}}$ & $28 \pm 10^{\mathrm{b}}$ \\
& Groups 1, 2, and 3 & 33 & $15 \pm 11^{\mathrm{x}}$ & $14 \pm 10^{\mathrm{x}}$ \\
Organic & Payoya (group 5) & 16 & $49 \pm 13^{\mathrm{c}}$ & $43 \pm 8^{\mathrm{c}}$ \\
& Serrana (group 8) & 10 & $21 \pm 6^{\mathrm{b}}$ & $26 \pm 10^{\mathrm{b}}$ \\
& Serrana (group 9) & 10 & $57 \pm 13^{\mathrm{d}}$ & $67 \pm 14^{\mathrm{d}}$ \\
& Groups 5, 8, and 9 & 36 & $47 \pm 19^{\mathrm{y}}$ & $45 \pm 19^{\mathrm{y}}$ \\
\hline
\end{tabular}

${ }^{\mathrm{a}-\mathrm{d}}$ Mean values with the same letters indicate homogeneous subsets for $P=0.05$ according to Tukey's honestly significant difference test.

${ }^{\mathrm{x}, \mathrm{y}}$ Mean values with different letters indicate homogeneous subsets for $P=0.001$.

${ }^{1}$ Only samples collected in April 2012. 
go into nutritional qualities and markers (e.g., HA) to distinguish organic milk in depth.

\section{ACKNOWLEDGMENTS}

The authors thank the Asociación de criadores de raza caprina Payoya (Algodonales, Cádiz, Spain), the Asociación nacional de criadores de ganado caprino de raza Florida (Córdoba, Spain), and Biogéminis S.L. (Moratalla, Murcia, Spain) for kindly supplying the milk samples studied. The financial support from the Spanish DGICyT (grat CTQ2011-23790) is also gratefully acknowledged.

\section{REFERENCES}

Besle, J. M., D. Viala, B. Martin, P. Pradel, B. Meunier, J. L. Berdagué, D. Fraisse, J. L. Lamaison, and J. B. Coulon. 2010. Ultraviolet-absorbing compounds in milk are related to forage polyphenols. J. Dairy Sci. 93:2846-2856.

Buiarelli, F., G. Cartoni, F. Coccioli, and R. Jasionowska. 2003. Capillary zone electrophoresis of some organic acids in milk whey. J. Sep. Sci. 26:425-428.

Carpio, A., V. Rodriguez-Estevez, M. Sanchez-Rodriguez, L. Arce, and M. Valcarcel. 2010. Differentiation of organic goat's milk based on its hippuric acid content as determined by capillary electrophoresis. Electrophoresis 31:2211-2217.

Collomb, M., W. Bisig, U. Bütikofer, R. Sieber, M. Bregy, and L. Etter. 2008. Fatty acid composition of mountain milk from Switzerland: Comparison of organic and integrated farming systems. Int. Dairy J. 18:976-982.

Council of the European Union. 2007. Council Regulation (EC) No. $834 / 2007$ of 28 June 2007 on organic production and labelling of organic products and repealing Regulation (EEC) No. 2092/91. Off. J. Eur. Union 189:1-23.

Dangour, A. D., S. K. Dodhia, A. Hayter, E. Allen, K. Lock, and R. Uauy. 2009. Nutritional quality of organic foods: A systematic review. Am. J. Clin. Nutr. 90:680-685.
Ellis, K. A., G. Innocent, D. Grove-White, P. Cripps, and W. G. McLean. 2006. Comparing the fatty acid composition of organic and conventional milk. J. Dairy Sci. 89:1938-1950.

Gatley, S. J., and H. S. A. Sherratt. 1977. Synthesis of hippurate from benzoate and glycine by rat-liver mitochondria. Submitochondrial localization and kinetics. Biochem. J. 166:39-47.

Gonthier, M. P., M. A. Verny, C. Besson, C. Rémésy, and A. Scalbert 2003. Chlorogenic acid bioavailability largely depends on its metabolism by the gut microflora in rats. J. Nutr. 133:1853-1859.

IFOAM. 2002. IFOAM Norms. II. IFOAM Basic Standards for Organic Production and Processing. International Federation of Organic Movements, Tholey-Theley, Germany.

Karabinos, J. V., and K. Dittiner. 1943. Presence of hippuric acid in milk. Proc. Soc. Exp. Biol. Med. 53:111-112.

Molkentin, J., and A. Giesemann. 2010. Follow-up of stable isotope analysis of organic versus conventional milk. Anal. Bioanal. Chem. 398:1493-1500.

Molkentin, J. D. J. 2009. Authentication of organic milk using $\delta 13 \mathrm{C}$ and the $\alpha$-linolenic acid content of milk fat. J. Agric. Food Chem. $57: 785-790$

Patton, S. 1953. The presence of hippuric acid in milk. J. Dairy Sci. 36:943-947.

Peinado-Lucena, E., M. Sánchez-Rodríguez, A. G. Gómez-Castro, C. Mata-Moreno, and J. A. Gallego-Barrera. 1992. Dry matter intake per mouthful by grazing dairy goats. Small Rumin. Res. $7: 215-223$

Rodríguez-Estévez, V., A. García, F. Peña, and A. G. Gómez. 2009. Foraging of Iberian fattening pigs grazing natural pasture in the dehesa. Livest. Sci. 120:135-143.

Scheline, R. R. 1991. Metabolism of oxygen heterocyclic compounds, flavonoids. Pages 267-290 in CRC Handbook of Mammalian Metabolism of Plants Compounds. R. R. Scheline, ed. CRC Press, Boca Raton, FL.

Sieber, R., U. Butikofer, and J. O. Bosset. 1995. Benxoic acid as a natural compound in cultured dairy products and cheese. Int. Dairy J. 5:227-246.

Svensen, A. A. 1974. Hippursyre og benzoesyre i melk og forskjellige meieriprodukter. Meieriposten 63:704-707.

Verhoog, H., M. Matze, E. Lammerts van Bueren, and T. Baars. 2003. The role of the concept of the natural (naturalness) in organic farming. J. Agric. Environ. Ethics 16:29-49. 